Ivana R. Gligorijević

Univerzitet u Beogradu

Filološki fakultet
$811.411 .21 ’ 374=163.4 * 3(038)$

https://doi.org/10.18485/analiff.2019.31.2.14

Originalni naučni rad

Primljen: 12.07.2019

Prihvaćen: 18.09.2019

\title{
REČI STRANOG POREKLA U KLASIČNOM ARAPSKOM JEZIKU: ARAPSKO-BOSANSKI RJEČNIK TEUFIKA MUFTIĆA
}

Rad se bavi rečima stranog porekla u klasičnom arapskom jeziku, koji se koristio pre pojave islama i u prvim vekovima po njegovom nastanku, a koji je intenzivno preuzimao reči iz persijskog, grčkog, sirskog, latinskog, hebrejskog i drugih jezika. Predstavljen je istorijski okvir u kom je dolazilo do jezičkih kontakata i navedeno 100 reči stranog porekla koje su ušle u klasični arapski jezik, razvrstanih prema etimološkom kriterijumu, uzimajući u obzir i intenzitet uticaja koji su pomenuti jezici izvršili na klasični arapski. Navedeni su prevodni ekvivalenti svake reči, i to na osnovu Arapsko-bosanskog rječnika Teufika Muftića (u prva dva izdanja: Arapsko-srpskohrvatski rječnik), pri čemu je identifikovano više reči stranog porekla koje se javljaju u oba jezika. Analizirali smo i druge podatke koje Muftićev Rječnik nudi u vezi sa pomenutim rečima stranog porekla - grafološke varijacije, morfološke odlike osnovnih oblika i množina izvedenih iz njih, kao i semantičke specifičnosti.

Ključne reči: reči stranog porekla, jezičko pozajmljivanje, adaptacija pozajmljenica, klasični arapski jezik, Arapsko-bosanski rječnik, Teufik Muftić.

\section{Terminološka određenja}

Pod terminom klasični arapski jezik se podrazumeva jezik kojim se govorilo na Arabijskom poluostrvu pre pojave islama i u prvim vekovima po njegovom nastanku (Muftić, 1998: 10). Ovaj se jezik bazirao na dijalektu plemena Kurejš, kojim je govorio prorok Muhamed i na kom je objavljena muslimanska sveta knjiga, Kuran. Pre pojave islama, ovaj je jezik bio pod uticajem jezika razvijenijih civilizacija sa kojima su Arabljani dolazili u kontakt. Kada je došlo do ekspanzije islama izvan granica Arabijskog poluostrva, na klasični arapski jezik su snažan uticaj izvršili jezici

* $\quad$ ivanamali@fil.bg.ac.rs 
naroda koji su se zatekli na osvojenoj teritoriji. Za narod koji je govorio klasičnim arapskim jezikom pre pojave islama, pa i nešto kasnije, Božović sugeriše da je najbolje koristiti termin Arabljani, dok nakon širenja islama, mešanjem Arabljana sa susedskim narodima, nastaje jedan sasvim novi narodni identitet, kojem bi više odgovarao termin Arapi (2018: 16).

\section{Kontakti Arabljana sa drugim narodima pre pojave islama}

Arabljani su od davnih vremena naseljavali Arabijsko poluostrvo, peščanu ravnicu sa retkim i međusobno udaljenim oazama, koja se na severu graniči sa zemljama „plodnog polumeseca“, na zapadu sa Crvenim morem, na jugu sa Indijskim okeanom, dok je na istoku zapljuskuje Persijski zaliv. Borba za život ovih ljudi u nepovoljnim pustinjskim uslovima bila je gruba, pa su većinu svoje energije trošili na zadovoljenje potreba svakodnevnog života. Prirodno okruženje i geografski položaj Arabijskog poluostrva odredili su način života njenih stanovnika - kako je najveći deo zemlje bio neplodna pustinja, oni su najvećim delom bili beduini, u stalnom pokretu i na niskom stepenu kulture, a glavne preokupacije su im bile su ratovanje, pljačke i stočarstvo. Sedelačko stanovništvo činili su seljaci, koji su naseljavali malobrojne plodne oranice, i gradsko, koje se bavilo trgovinom i zanatima. Predislamska Arabija je bila posrednik u trgovini između Istoka i Zapada, pa su kroz njene gradove, koji su imali ulogu trgovačkih centara, prolazili karavani za Daleki istok i okupljali se strani putnici i trgovci (Nuri Hadžić, 1987: 41, 50-51; Lewis, 1993: 15; 2001: 409; Hurani, 2013: 47).

Arabija predislamskog doba se graničila sa tadašnja dva moćna carstva - na zapadu sa Vizantijskim, koje je usvojilo hrišćanstvo prožeto helenističkom kulturom, a na istoku sa Sasanidskim, koje se priklonilo drevnoj iranskoj i semitskoj kulturnoj tradiciji, a za zvaničnu veru uzelo zoroastrizam. Zbog svog strateškog položaja, Arabija je bila stalni predmet interesovanja Vizantinaca i Sasanida. Ova dva carstva su održavala tamponske slojeve, kao prelaz od vizantijske i sasanidske civilizacije ka anarhičnom životu pustinje - Lahmide, nestorijanske hrišćane, čiji je glavni grad bio Hira na rubu Mesopotamije, u zoni nad kojom Sasanidi nisu imali neposrednu kontrolu, i Gasanide, sledbenike monofizitskog hrišćanstva, koji su pod sličnim uslovima nastanjivali jednu regiju u okviru Vizantijskog 
carstva, na ivici sirijske pustinje. Upravo preko ovih kanala su se u srce paganske Arabije infiltrirali persijski, aramejski, helenistički i vizantijski kulturni uticaji (Gabrijeli, 1985: 19; Hiti, 1988: 111; Lewis, 1993: 27; 2001: 50; Espozito, 2002: 11-12, 14; Hurani, 2013: 43-44, 46, 48).

Svoj uticaj na Arabljane su vršile i manje jevrejske zajednice, čije je uporište bilo u zemljoradničkim oazama Hidžaza, naročito u Medini, kao i u Jemenu (Gabrijeli, 1985: 19; Lewis, 1993: 27; 2001: 50). Poznato je da su Arabljani u ovo vreme imali kontakte i sa Abisinijom (današnjom Etiopijom), drevnom kraljevinom u kojoj je koptsko hrišćanstvo bilo zvanična religija. Kontakti Arabljana sa Abisinijom su se odvijali preko Jemena, na jugozapadu Arabijskog poluostrva, gde su Abisinci uspostavili vlast otprilike pedeset godina pre rođenja proroka Muhameda. Između Arabijskog poluostrva i Abisinije je, u to vreme, postojao aktivan pomorski saobraćaj, a Jemen je služio kao tranzitna tačka za trgovinu između udaljenih mesta (Jeffery, 1938: VII; Hiti, 1988: 110; Lewis, 1993: 28; Hurani, 2013: 46).

Kroz kontakte sa susednim narodima i preko trgovačkih puteva, do Arabljana su dolazile određene predstave o okolnim razvijenijim zemljama i njihovoj kulturi. Posebno veliki odjek u različitim delovima Arabije imale su religijske tendencije, pa ne iznenađuje činjenica da su reči koje su u klasični arapski jezik ušle u ovom periodu pretežno religijskog karaktera. Čak i muslimanska sveta knjiga, Kuran sadrži određene monoteističke principe preuzete iz judaizma, hrišćanstva i manihejstva - elemente iz tradicija koje su u to vreme i na tom mestu bile dostupne Muhamedu - kao i jedan broj reči stranog porekla koje se na date pojmove odnose (Lewis, 1992: 14; Espozito, 2002: 14; Hurani, 2013: 49, 58-59).

Arabljani su se preko razvijenijih civilizacija susreli i sa drugim pojmovima koje je trebalo imenovati, pa je jezik ovih ,sinova pustinje“ preuzeo mnoge nazive za biljke, životinje, artefakte i sve one kulturno obojene termine koji su označavali pojmove strane njihovom neposrednom okruženju. U rano doba arapski je primio reči iz persijskog, aramejskog (preko njega i akadskog), sirskog, etiopskog, koptskog, hebrejskog, grčkog, latinskog, sanskrita i drugih jezika (Muftić, 1998: 12; Kico, 2003: 237), a najveći trag na arapski vokabular ostavili su jezici čiji su govornici bili na višem civilizacijskom nivou. Uticaji pomenutih jezika na arapski nastavili su se i nakon pojave islama, kada se sa usmenog sve više prelazilo na pozajmljivanje pismenim putem. 


\section{Kontakti Arabljana sa drugim narodima nakon pojave islama}

Nakon pojave islama nastavljaju su kontakti Arabljana sa hrišćanskom Vizantijom, čiju su prestonicu, Carigrad, više puta bezuspešno pokušavali da osvoje. Za vreme Umajadskog halifata (661-750) ratovi i osvajački pohodi bili su najčešći vid kontakata Arabljana sa strancima. Umajadi su, u svojim vojnim pohodima, uspeli da zauzmu ogromnu teritoriju - na zapadu su preko severne Afrike i Gibraltara došli su do Španije, a na istoku, preko teritorija današnjeg Irana i centralne Azije, sve do Indije. Tako se u islamskoj imperiji zateklo mnoštvo naroda i stvorilo plodno tlo za jezičke uticaje (Gabrijeli 1985: 9-10; Hiti, 1988: 201-205; Mansfield, 1992: 14; Lewis, 2001: 410-411; Hurani, 2013: 64-71). Arabljani, koji su do tada pripadali pretežno nomadskoj i zatvorenoj zajednici, bez ikakve naučne baštine i kulturne tradicije, našli su se kao učenici pred narodima bogatih i starih kultura, koje su vojnički pokorili (Tanasković, 1982: 36; Hiti, 1988: 228).

Za vreme Abasidskog halifata (750-1258), islamska kultura dostigla je svoj vrhunac. U prvim decenijama abasidske vladavine dominirali su strani uticaji, koji su znatno doprineli duhovnom buđenju Arapa. Snažan uticaj na oblikovanje arapskog jezika imali su, pre svega, nearapi - pokoreni narodi koji su primili islam i koji su bili motivisani da uče arapski jezik. Upravo su oni i bili prvi prevodioci stranih dela na arapski jezik. $\mathrm{U}$ ovom periodu dolazi do intenzivnijeg pozamljivanja pismenim putem, zbog prevođenja stranih dela na arapski, sa persijskog, sanskrita, sirskog i grčkog (Gabrijeli, 1985: 10-11; Hiti, 1988: 287-288, 283-284; Mansfield, 1992: 14-16; Muftić, 1998: 11; Holes, 2004: 306; Hurani, 2013: 71-76).

Kontakti sa persijskom kulturom bili su najintenzivniji upravo u vreme Abasidskog halifata, kada je persijski uticaj bio je najizraženiji u književnosti. Što se tiče indijskog uticaja, on je bio najzastupljeniji u oblasti filozofije, književnosti, matematike i astronomije (Hiti, 1988: 285). Grčki uticaji su, u ovo vreme, bili vrlo intenzivni. Helenizam se, kako zapaža Hiti, ,pokazao najvitalnijim od svih stranih uticaja u arapskom životu“, a širio se iz Edese, centra hrišćanskih Sirijaca, iz Harana, sedišta paganskih Sirijaca, iz Antiohije, jedne od mnogih starih grčkih kolonija, iz Aleksandrije, stecišta istočne i zapadne filozofije, i iz bezbroj manastira u Siriji i Mesopotamiji, gde su negovane, crkvene nego i naučne i filozofske studije 
(Hiti, 1988: 286). U ovom periodu mnoga klasična dela prevedena su na arapski (na taj način su očuvana brojna umetnička i naučna dela antičke Grčke, čiji originali nisu sačuvani). Dela su često prevođena i preko jezika-posrednika - mnoga grčka dela bila su prvo prevedena na sirski jezik, a potom na arapski (Hiti, 1988: 287-288; Kico, 2003: 132-134)

\section{Reči stranog porekla u klasičnom arapskom jeziku}

Navešćemo 100 reči stranog porekla iz najčešćih jezika-davalaca, čije smo prevodne ekvivalente eskcerpirali iz Arapsko-bosanskog rječnika Teufika Muftića (1997), zajedno ostalim dostupnim podacima. Ovaj rečnik je prvi put objavljen pod nazivom Arapsko-srpskohrvatski rječnik I i II (1973) i imao je više izdanja. U trećem izdanju, koje je objavljeno 1997, u skladu sa stvarnošću koja je nastala posle ratova na području SFRJ, preimenovan je u Arapsko-bosanski rječnik (Duraković, 2004: 13).

Za njega smo se opredelili jer sadrži obiman izbor reči iz starijeg perioda, od kojih su mnoge izašle iz žive upotrebe, dok su pojedini oblici pretrpeli bitne promene značenja, pa je posebno dragocen za rad na građi iz oblasti klasične filologije (Tanasković, 1976: 200-201; Duraković, 2004: 14). Rječnik predstavlja riznicu arapske leksike i ,jedan od najvrednijih rezultata jugoslovenske orijentalistike uopšte“ (Mitrović, 2010: 205). Mitrović s pravom konstatuje da je ovaj rečnik „,svakom arabisti najpotrebniji priručnik“ (2010: 205), a Tanaskovićeva ocena, od pre četiri decenije, da on ,staje u red najvrednijih rezultata naše orijentalistike, čije će napredovanje sigurno ubrzati“", neosporno i danas važi (1976: 202).

U njega je Muftić uključio vrlo veliki korpus literature iz oblasti leksikografije arapskog jezika, od opštih do stručnih, specijalizovanih i terminoloških rečnika iz raznih naučnih oblasti, zbog čega Tanasković ocenjuje da ovo delo ima karakter „visokonaučne kompilacije“ (1976: 201). Autor je na rečniku radio petnaestak godina i obradio oko 150.000 reči i izraza na skoro 4.000 strana (Tanasković, 1976: 201; Duraković, 2004: 13; Mitrović, 2010: 205). Rječnik je organizovan po alfabetskom redosledu, prema korenskim konsonantima, a u njega je unesen i priličan broj stranih reči, naročito iz oblasti nauke, tehnike i nekih drugih posebnih domena života (Muftić, 1997: X). Značajan deo reči stranog porekla u njemu čine termini (botanika, medicina, zoologija, hemija, muzika, anatomija, mineralogija, 
fizika, patologija, ornitologija, astronomija...), etnonimi, lingvonimi, toponimi i iz njih izvedeni prisvojni pridevi.

Radi lakšeg pronalaženja stranih reči, čiji se suglasnici podudaraju sa radikalima nekog arapskog korena, ti oblici su u Rječniku navođeni pod datim korenom, uz naznaku da ih treba tražiti po abecednom redu. Na primer, persijska reč hazār se može naći pod korenom *hzr, uz napomenu $\rightarrow a b t$, a ako je potražimo po alfabetskom redosledu, naćićemo: hazār mn. ät-slavuj (Muftić, 1997: XI-XII). U svom rečniku, Muftić strane reči označava simbolom ${ }^{\circ}$. Pored toga, simbolom $\Delta$ označene su reči nesigurnog porekla, prastare arabizovane pozajmljenice, dijalekatski oblici ili kovanice, kao i reči nepravilnog oblika (Muftić, 1997: XV). Prema našoj proceni, ovaj rečnik sadrži oko 10.000 odrednica koje su označene datim simbolima.

\subsection{Reči iz persijskog jezika}

Pošto su veze Arapa sa Persijancima kroz istoriju bile vrlo jake, ne iznenađuje to što je u klasični arapski jezik najveći broj stranih reči ušao upravo iz persijskog. Ove reči pokrivaju različite aspekte svakodnevnog života - hranu, biljke, odeću, posuđe, alate, profesije, životinje, administraciju, politiku, nauke, književnost, društveni život i druge oblasti, a mnoge od njih su danas u upotrebi, o čemu svedoče sledeći primeri:

bābū̆ğ mn. bawābï̌̆ - papuča;

baht mn. abhāt, buhūt - sreća; vrsta lutrije;

banğara mn. banāğir - (okrugao) otvor; prozor, pendžer;

bundār mn. banādira - trgovac;

bustān mn. basātīn - vrt, povrtnjak, bostan; voćnjak;

dihlìz mn. dahālìz - predvorje, trijem, vestibul; hodnik; katakombe; galerija;

dustūr mn. dasātīr - ustav; statut; uzorak, mustra; registar; pravilo; poredak; dostojanstvenik; ministar; dozvola; plural takođe $=$ persijske vjerske knjige;

dušmān - neprijatelj, dušman;

fanğān mn. fanāğin - findžan, šoljica;

fayrūz, firūz - tirkiz; diptoton - imenica sa dvopadežnom promenom $=$ Fejruz, Firuz - npp.; 
firind mn. farānid - zrno šipka; mač, sablja; dragulj (ukras, šara) na maču; svilena tkanina; sjaj, blijesak;

ğām mn. āt, ağwām, ağ um, ğūm - čaša; pehar; šolja; izlog;

ğawhar (a) mn. ğawāhir - bit, suština; sadržina; tvar, materija, supstanca; atomi; dragulji; Dževher - npp. /plural takođe: juvelirski radovi/;

ğawrab mn. ğawārib, ğawāriba - čarapa;

ibrīq mn. abārīq, abāriqa - ibrik;

ibrīsam - svila; ibrišim;

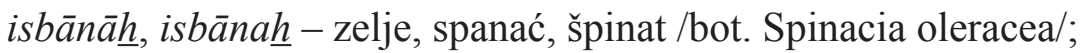

istabraq - brokat;

mă̌ūs - obožavaoci vatre, magi, medžusije; grijesi/;

să̌̆ll, siğğğl - okamenjena glina /u paklu na k. su popisani ljudski

sirwāl (a) mn. sarāwīl, sarāwilāt - hlače, pantalone; šalvare; gaće;

tāğ mn. tīğān - kruna, dijadem, vijenac; turban; mitra /biskupa/; kresta, hober; griva; lav; kruna /zuba/;

ustāa mn. ùn, asātida, asātī $\underline{d}$ - učitelj; profesor, umjetnik; obrtnik; zanatlija, majstor; maestro; meštar; gospodin; starješina; trgovački temin = glavna knjiga;

usțuwāna mn. usțuwānāt, asāțīn, asāțina - stup; valjak, cilindar; (gramofonska) ploča; bubanj /turbine/; /čelična/ boca; rezervoar/gasa/;

yāsamīn, yāsmīn - jasmin; Jas(e)min;

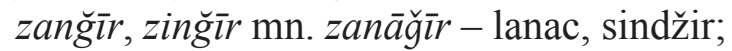

zindīq mn. zanādiqa, zanādīq - manihejac, dualist; raskolnik, heretik; nevjernik, bezbožnik, ateist; bigot, dvolični bogomoljac

i mnoge druge (Jeffery, 1938: 6-7; Nahla al-Yasū'ī, 1945: 100-111; Hiti, 1988: 92, 111; Muftić, 1997; al-Munğid, 2001; Bāsil, 2002: 9).

\subsection{Reči iz grčkog jezika}

Od grčkih reči u arapskom jeziku, mnoge su ušle preko aramejskog, kao jezika-posrednika. U ovom leksičkom sloju nalazi se mnogo reči koje se odnose na hrišćanstvo, nauke i filozofiju, a zastupljene su i druge tematske oblasti, o čemu svedoče i sledeći primeri: rubtahta;

asțurlāb - /sprava za mjerenje udaljenosti zvijezda/ astrolabij, 
bațrīq, bițrīq mn. bațārīq, bațāriqa - patrijarh; general, (rimski) vojskovođa; patricij; orn. = pingvin /ohol, ponosan/;

bayțār mn. bayāțira - potkivač; veterinar, živinar;

falsafa - filozofija;

iblīs - vrag, đavo, demon, iblis;

$i k s \bar{r}$ - eliksir; kamen mudrosti;

inbīq mn. anābīq - alembik, prekapnica /kotao za destilaciju/;

inğ̄l $\mathrm{mn}$. anāğ $\bar{l}$ - evanđelje, indžil;

iqlìd - ključ;

iqlìm mn. aqālìm - klima, podneblje; predio, kraj; oblast, pokrajina, provincija; kotar, srez, okrug, distrikt /plural takođe = zemlja, oblast, pokrajina;

isfanğ (a) mn. $\bar{a} t$ - spužve, sunđeri;

kimiya '- kemija; alkemija;

qașdīr, qișdīr (a) - kalaj, kositar;

qirțās, qarțās, qurțās mn. qarāțīs - papir, hartija; list (svitak) papira; spis; knjiga; meta, cilj /od kože/; kornet;

țilsam mn. àt, talāsim - zapis, talisman; tajno pismo, kriptografija; tajna;

uhțubūt - oktopod, hobotnica - zo;

urg̈un mn. arägin - orgulje;

usquf mn. as āqifa, as āqif- biskup; paroh; episkop, vladika; prelat;

usțūl mn. as ățīl - brodovlje, flota; eskadrila;

usțūra mn. asāțīr - priča, bajka; legenda, mit;

i mnoge druge (Nahla al-Yasū'î, 1945: 113-117; Ma'rūf, 1960: 1011; Muftić, 1997; al-Munğid, 2001; Bāsil, 2002: 13-14; Kico, 2003: 236).

\subsection{Reči iz sirskog jezika}

Sirski, jezik sirijskih hrišćana u Vizantijskom carstvu, dao je arapskom reči koje se uglavnom odnose na hrišćansku religiju, ali i na druge pojmove strane beduinskom okruženju. Ovaj jezik, koji je i danas u liturgijskoj upotrebi, bio je posrednik za prevođenje mnogih grčkih naučnih i filozofskih dela na arapski. Iz njega je arapski pozajmio nazive za mesece u godini, kao i brojne druge reči, poput sledećih koje smo ekscerpirali iz Rječnika: 
bī'a mn. àt, biya' - crkva; sinagoga;

tannūr mn. tanānīr - peć i

tilmī $\underline{d}$ mn. talāmī $\underline{\text { }}$, talāmi $\underline{d}$ a - učenik; šegrt, naučnik; student; kadet.

Mnoge aramejske reči u Rječniku nisu označene kao strane (iako smo u drugim izvorima potvrdili njihovu etimologiju), kao na primer:

dayr mn. adyār, adyira, duyūr - samostan, manastir, kloster;

dumya mn. àt, duman - kip, statua, spomenik; slika; idol; lutka; marioneta; žena; maneken; utvara;

ka's mn. āt, ak'us, ku'ūs, ki' ās - čaša; pehar; bokal; kalež; kup; bot. = čaška, čašica; vino;

kāhin mn. kuhhān, kuhun, kahana - vrač; prorok; svećenik; upravitelj; nadzornik;

nìr mn. anyār, nīrān - jaram, igo; strana (ili trasa) puta;

qissīs mn. ūna, aqissa, qussān, qasāwisa - svećenik, župnik, pastor; raḥmān - premilostiv (Bog) milosrdnik; c. art. = naziv 55. poglavlja Q./;

șadaqa mn. àt - milostinja, sadaka; tak. = șadāq;

șalīb mn. șulub, șulbān - križ, krst; moždina, srž /iz kosti/; zastava; skupina od deset hiljada /vojnika/;

șanam mn. așnām - idol, kumir; dragi.

Značajan broj reči aramejske etimologije označen je simbolom $\Delta$, čime se verovatno ukazuje na prastare arabizovane pozajmljenice:

faddān mn. fadādīn - vo; jaram (volova); plug; za dan uzorano; njiva; fed(d)an /oko 4200m2/;

kanīsa mn. kana ' is - crkva; sinagoga; templ, hram; ljepotica; stidljiva povučena djevojka; zaklon /na nosiljci ili sedlu (Mufić ne navodi da ovo strana reč, ali navodi za pridev kanīsì);

malakūt - vlast, suverenitet; kraljevina; carstvo; nevidljivi svijet; carstvo nebesko;

nāțūr mn. nawāțīr - čuvar; pudar; stražar na jarbolu; dijamantni ukras /na čelu žene/;

šammās mn. šamāmisa - đakon; misnik;

zabūn mn. zubun, zaba 'in - glupak, kupac, mušterija, klijent; partner; gost; dragi (nije označena kao strana, ali jeste u drugom značenju „potkošulja“, „steznik“ i „,vrat“", sa množinom azbina); 
i druge (Nahla al-Yasū's̄i, 1945: 118-120; Hiti, 1988: 105; 111; Muftić, 1997; al-Munğid, 2001; Holes, 2004: 305).

\subsection{Reči iz latinskog jezika}

Latinske reči su u arapski ulazile preko jezika-posrednika, kao na primer reč qindīl koja je došla preko aramejskog, a potiče od latinske reči candela. U Rječniku je predstavljena na sledeći način:

qindīl mn. qanādīl-svjetiljka, lampa; fenjer, kandilj; svijećnjak (ne navodi se da je stranog porekla).

S druge strane, Rječnik je naznačio stranu etimologiju kod reči qașr, koja potiče od latinske reči castrum, a ušla je preko aramejskog:

qașr mn. qușūr - dvorac, zamak; palača; dom; grad, kaštel; c. art. $=$ Kasr /npl. u Egiptu, Siriji i dr./; Alkazar /ime dvorca u više španskih gradova/.

Isto važi i za reč șirāt, za koju se pretpostavlja da je preko grčkog i aramejskog ušla u arapski, a da vodi poreklo od latinske reči strata:

șirāt mn. șurut - put

(Jeffery, 1938: 195-196; Hiti, 1988: 111; Muftić, 1997; al-Munğid, 2001; Holes, 2004: 305).

Od ostalih latinizama u Rječniku, izdvojićemo sledeće:

balāt mn. ablița - dvor; dvorac, palača;

dīnār mn. danānīr - (zlatni) dinar, zlatnik, dukat /pl. tak. = novac, novci; Denanir /ime žene/;

furn mn. afrān - (krušna) peć, pecara; roštilj; ležište /lokomotive/;

imbarāțūr mn. imbrāțira, abāțira, barāțira - car, imperator;

istabl mn. àt-staja, konjušnica;

$k \bar{u} b$ mn. $a k w \bar{a} b$ - čaša, pehar /bez drška i izliva/;

qamīṣ mn. aqmiṣa, qumuṣ, qumșān - košulja; kr. = alba, misna košulja; oklop; prevlaka, omot(ač), plašt; utelovljenje, inkarnacija;

qayșar mn. qayāșir, qayāṣira - car, ćesar; Cezar - npp.;

qințār mn. qanāțīr - kantar/mjera od 100 ratl-ova ili 36 oka $=44,928$ kg. odn. 256,4 kg/; talent /tj. 1000 i više zlatnih dinara/;

siğill, suğull mn. àt - svitak, smotak; protokol, registar; dnevnik; knjiga; sidžil; spisak, lista, popis; pisar, bilježnik, notar; čovjek; Sidžill / npp. ili ime anđela/ - /plural takođe $=$ arhiv 
$\bar{u} q i y y a \mathrm{mn} . \bar{a} t$, awāqin, awāqiyy $-\mathrm{oka} / \mathrm{Haleb}=320 \mathrm{~g}$. Jerusalim $=$ $240 \mathrm{~g}$; Bejrut $=213,3 \mathrm{~g}$; Kairo = 37,44 g/;

i mnoge druge (Nahla al-Yasū‘̂̄, 1945: 126-127; Bāsil, 2002: 15; Muftić, 1997; al-Qinai, 2000: 4; al-Munğid, 2001).

\subsection{Reči iz hebrejskog jezika}

Od ostalih stranih reči u klasičnom arapskom jeziku možemo izdvojiti one koje su došle iz hebrejskog, a odnose se na religiju:

(al-) talmūd-Talmud /zbirka jevr. predanja i zakona, nastala između II i VI vijeka n.e./;

àmin, amin - amin, amen /neka bude tako!/;

fașh, fiṣh - Uksrs, Vaskrs; Pasha; poskog);

ğahannam (imenica ženskog roda) - pakao, džehennem (preko eti-

sabt mn. asbut, subūt - subota; dio vremena, vrijeme; sedmica; prepredenjak; hrabar dječak; pospanac; izvrstan konj; brzi hod /deva/;

šayțān mn. šayāțīn - vrag, đavo, demon, sotona, šejtan; napasnik, zavodnik; oholost; srdžba; žig /na nozi deve, od kuka preko buta do koljena/; zmija; vragolan, obješenjak; bezbožan; ohol; zloban; prgav; zao, opak; podmukao, lukav; bučan; nestašan, nemiran; brbljav;

tawrā mn. $\bar{a}$ - Tevrat, Tora, Pentateuh; Stari Zavjet

i druge (Nöldeke, 1910: 47; Nahla al-Yasū‘̄i, 1945: 122-123; Muftić, 1997; al-Munğid, 2001).

\subsection{Reči iz etiopskog jezika}

Uticaj etiopskog jezika na arapski vidi se brojnim pozajmljenicama koje su uglavnom religijskog karaktera:

burhān mn. barāhīn - dokaz, argumenat; jasan znak; odluka, knez, prvak, vođa;

ḩawārī mn. ūn-pomoćnik; sljedbenik; učenik /vjerovjesnika/; apostol; bjelilac /rublja/; prijatelj;

mā'ida mn. àt, mawā'id - sto (s jelom), trpeza; jelo; okrug; okruglo zemljište; /sa članom = naslov 5. poglavlja Q/; 
miḥrāb mn. mah̄ārīb - pročelje, fasada; najbolje (odvojeno) mjesto; dvorac; soba; leglo (lava); polukupola; skup, zbor, sastanak; sinagoga;

minbar mn. manābir - propovjedaonica; mimbera; govornica; katedra; tribina;

mușhaf, mașhaf, mișhaf mn. mașāhif - svezak; knjiga;

munāfiq - licemjer, dvoličnjak;

ğibt - idol; čarobnjak; čarolija, magija i sl. (Fraenkel, 1886: 248; Nöldeke, 1910: 49-50, 58-59; Jeffery, 1938: 77-78, 192-194, 269, 272; Bāsil, 2002: 11; Hiti, 1988: 110; Muftić, 1997; al-Munğid, 2001).

\subsection{Reči iz drugih jezika}

U arapski su ušle i reči iz drugih jezika. Iz sanskrita:

aruz, aruzz, urz - riža, pirinač /bot. Oryza sativa/;

kāfūr - kamfor; kamforovo drvo /bot. Cinnamomum camphora odn. Camphora officinanum/; eukalipt, gumino drvo /bot. Eucalyptus globulus/;

zanğabĭl - vino; Zendžebil /ime rajske rijeke/; isiot, đumbir, ingver, zendžefil /bot. Zingiber officinale odn. Amomum zingiber/.

Iz asirskog:

harūb (a) - rogači, roščići /bot. Ceratonia siliqua/;

simsim (a) - sezam /bot. Sesamum indicum/; zrnje korijandra, paprića /bot. Coriandrum/ (preko grčkog) i sl.

(Hiti, 1997: 478; Muftić, 1997; al-Munğid, 2001),

\subsection{Nedoslednosti kod navođenja etimologije pojedinih reči}

Bez obzira na korišćenu relevantnu literaturu pri identifikaciji pozajmljenica, navedene činjenice treba uzeti s određenom rezervom, jer ne možemo uvek sa sigurnošću tvrditi da je data reč ušla u arapski iz određenog jezika, niti da je ušla u određeno vreme (osim ako o tome ne svedoče neki pisani izvori, poput, recimo, Kurana). Strana reč ulazi u jezik bezbroj puta, preko raznih prenosilaca, izlazi iz mode i ponovo se vraća, da bi tek posle mnogo stotina ili hiljada upotreba postala stalni deo leksičkog fonda (Klajn, 1971: 13-14). Po tom pitanju ni literatura koju smo koristili nije usaglašena - dok jedan izvor navodi jezik-posrednik preko kog je data reč ušla u klasični arapski jezik, drugi izvor navodi poreklo reči, bez obzira na jezik-posrednik preko kog je ušla u arapski. Tako, na primer, rečnik 
al-Munğid navodi da je üqiyya pozajmljenica iz grčkog, iako je reč o leksemi latinskog porekla (izvorno: uncia), kako navodi Online Etymology Dictionary (OED). Nahla navodi da je reč zanğabīl persijskog porekla, prema rečniku al-Munğid ova reč dolazi iz grčkog, dok $O E D$ navodi da reč najverovatnije dolazi iz sanskrita (Nahla al-Yasū's', 1945: 105; al-Munğid, 2001: 623). Na više mesta u Rječniku nema nikakve naznake da je u pitanju reč stranog porekla, mada drugi izvori tvrde suprotno. Dok Hiti (1988: 92) navodi da je od persijske reči zandīk (mađioničar; manihejac, heretik) izvedena arapska reč zandaqa, nju i njene derivate Mufić ne beleži kao strane (1997: 604). Čak i reč za vrhovno božanstvo paganske Arabije, $H u$ bal, kako navodi Hiti, vodi poreklo iz aramejskog jezika i znači para, duh, mada u Muftićevom rečniku nije navedena kao strana (Hiti, 1988: 105; Muftić, 1997). Možda su ovi i slični „propusti“ nastali zbog preobimnog posla koga se Muftić prihvatio na kompilaciji različitih rečničkih izvora, a možda je autor ovako postupio svesno i sa određenom namerom.

Za jedan broj reči koje Muftić nije označio kao strane smo sigurni da je to urađeno svesno. Reč je o pozajmljenicama semitskog porekla (najviše iz sirskog) koje su se lako arabizovale, zahvaljujući trokonsonantskom sistemu, istim korenima i istim morforoškim karakteristikama kod jezika iz semitske porodice. Iako forma datih reči ne ukazuje na strano poreklo, sadržina jasno ukazuje na to da su ove reči, budući hrišćanske tematike, morale biti preuzete iz neke druge kulture.

Što se tiče pozajmljenica iz semitskih jezika koje imaju neke morfološke odlike zajedničke sa arapskim, ali su su zadržale i obeležja strane forme, u Muftićevom rečniku ćemo ih pronaći pod simbolom $\Delta$, kao što je slučaj sa sirskom rečju malaküt - kraljevina; carstvo. Data reč se nalazi pod arapskim korenom *mlk, koji označava pojmove vladavine i posedovanja i od koga su izvedene mnoge reči izvorno arapskog porekla (Holes, 2004: 305-306). Kod Muftića je ova reč naznačena simbolom $\Delta$, jer arapski ne izvodi reči pomoću sufiksa - $\bar{u}$, što je karakteristika akadskog, hebrejskog i sirskog (Moscati, Spitaler i dr., 1964: 83).

\section{Analiza ekscerpiranog materijala}

\section{1. Stepen adaptacije}

Reči stranog porekla u klasičnom arapskom jeziku možemo podeliti na one čije se strano poreklo ne oseća i koje je pogodno zvati arapskim 
rečima stranog porekla, i one čije je adaptacija poodmakla, ali je strano poreklo i dalje očigledno, a koje bi se s pravom mogle nazvati pozajmljenicama. U arapskom jeziku se za ova dva pojma koriste termini kalima mu 'arraba i kalima dahilla, prvi za potpuno adaptirane (arabizovane) strane reči, a drugi za one koje nisu dostigle taj stepen adaptacije (Bāsil, 2002: b; 'Ubayd, 2001: 113).

Od ukupno 100 ekscerpiranih reči, većina je na visokom stepenu grafološke adaptacije, pa postoji samo po jedan grafološki oblik kod svake od njih. S obzirom na to da su ove reči u arapski ušle u najranijim fazama njegovog razvoja, visok stepen grafološke (i fonološke) adaptacije je i bio očekivan rezultat (Klajn, 1966: 433-443; Janković, 1987: 129). Kod 10 reči primećeno je da imaju po 2 grafološke varijante, dok smo samo kod 3 reči uočili da imaju po 3 različite grafološke varijante. Pošto su pomenute varijacije uglavnom vezane za kratke vokale, koji se u arapskom beleže samo u određenim situacijama i za određene potrebe, one nisu toliko uočljive na grafološkom nivou, koliko su primetne na fonološkom. O tome svedoče sledeći primeri: siğill, suğull; qirțās, qarțās, qurțās; aruz, aruzz, urz i drugi. Ređe su javljaju grafijska kolebanja kod pisanja iste reči sa ili bez slova koja označavaju duge vokale (kao na primer: isbānāh $\underline{h}$ isbāna $\underline{h}$ ).

Mali broj reči stranog porekla se u arapskom adaptirao u trokonsonantski sistem i njegove tvorbene obrasce. Zapravo, najveći broj ovakvih adaptacija primetićemo kod reči iz sirskog ili etiopskog, koje su i u jezikudavaocu bile sastavljene od trokonsonantskih korena po tvorbenim obrascima tipičnim za semitske jezike - reči kao što su kāhin, șadaqa, mușhaf ili ğibt jasno svedoče o tome. Kada je reč o ukupnom ekscerpiranom materijalu, najfrekvetniji tvorbeni obrasci su četvorokonsonantski, jer su znatno pogodniji da adaptaciju reči koje dolaze iz indoevropskih jezika. Najproduktivniji je bio obrazac $\mathrm{C}_{1} \mathrm{iC}_{2} \mathrm{C}_{3} \overline{1} \mathrm{C}_{4}(15)$, a potom $\mathrm{C}_{1} \mathrm{uC}_{2} \mathrm{C}_{3} \overline{\mathrm{aC}}_{4}(6)$, $\mathrm{C}_{1} \mathrm{aC}_{2} \mathrm{C}_{3} \overline{\mathrm{a}} \mathrm{C}_{4} \mathrm{i} \mathrm{C}_{1} \mathrm{iC}_{2} \mathrm{C}_{3} \overline{\mathrm{a}} \mathrm{C}_{4}(4), \mathrm{C}_{1} \mathrm{aC}_{2} \mathrm{C}_{3} \overline{\mathrm{i}} \mathrm{C}_{4} \mathrm{i} \mathrm{C}_{1} \mathrm{aC}_{2} \mathrm{C}_{3} \mathrm{aC}_{4}(3)^{1}, \mathrm{C}_{1} \mathrm{uC}_{2} \mathrm{C}_{3} \overline{\mathrm{u}}_{4}$ (2), dok se ostale višekonsonantske reči ne mogu svesti na neke ustaljene obrasce, naročito one koje imaju po pet, šest ili više konsonanata.

Za reči koje su u arapskom razvile oblike množine, naročito one slomljene, možemo reći da su na visokom stepenu morfološke adaptacije, a takva je većina reči iz našeg ekscerpiranog materijala. Od ukupno 100 reči,

1 Za ovaj obrazac $(\mathrm{C} 1 \mathrm{aC} 2 \mathrm{C} 3 \mathrm{aC} 4 \mathrm{u})$ se navodi da je tipična za reči strane etimologije u semitskim jezicima (Moscati, Spitaler i dr., 1964: 84). 
kod 70 su zabeleženi oblici množine. Najpogodniji su bili sledeći tvorbeni obrasci: $\mathrm{C}_{1} \mathrm{aC}_{2} \overline{\mathrm{a}} \mathrm{C}_{3} \mathrm{iC}_{4}(31), \mathrm{C}_{1} \mathrm{aC}_{2} \overline{\mathrm{a}} \mathrm{C}_{3} \mathrm{iC}_{4}$ (13) i obrazac $\mathrm{C}_{1} \mathrm{aC}_{2} \overline{\mathrm{a}}_{3} \mathrm{iC}_{4} \mathrm{a}$ (12), koji je na jednom mestu čak i proširen, da označi množinu šestoradikalne reči, na formu $\mathrm{C}_{1} \mathrm{C}_{2} \mathrm{C}_{3} \mathrm{C}_{4} \overline{\mathrm{a}} \mathrm{C}_{5} \mathrm{iC}_{6} \mathrm{a}$ (reč je o leksemi imbrāțira). Uz ove oblike, učestala je i sufiksalna množina ženskog roda, $-\bar{a} t$ (13), a nešto manju učestalost imaju i oblici $\mathrm{aC}_{1} \mathrm{C}_{2} \overline{\mathrm{a}} \mathrm{C}_{3}(7), \mathrm{C}_{1} \mathrm{uC}_{2} \overline{\mathrm{u}} \mathrm{C}_{3}(5) \mathrm{i} \mathrm{C}_{1} \mathrm{uC}_{2} \mathrm{uC}_{3}(5)$, $\mathrm{aC}_{1} \mathrm{C}_{2} \mathrm{iC}_{3} \mathrm{a}$ (4) i drugi manje frekventni oblici, koji više odgovaraju arapskim trokonsonantskim rečima, nego višekonsonantskim rečima stranog porekla.

U grupu onih 30 reči kod kojih nisu zabeleženi oblici množine, spada više reči koji prirodno ne mogu imati množinu, poput apstraknih, gradivnih ili vlastitih imenica (malakūt; qașdīr/qișdīr; yāsamīn/yāsmīn itd.), reči koje su ograničene samo na jedan kontekst i jedan oblik (na primer, $u$

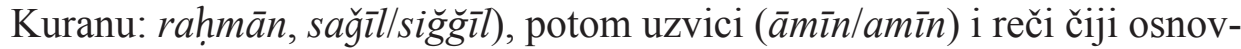
ni oblik već označava množinu (mağus). Znatno je manji broj imenica koje bi mogle razviti oblike množine, i koje ih možda imaju, a Rječnik to ne beleži (iqlīd, munāfiq, asțurlāb itd).

Neke reči koje su se uklopile u tro- ili četvorokonsonantski sistem arapskog jezika su ostvarile svoj derivacioni potencijal i kod glagola, glagolskih imenica i iz njih izvedenih participa. U Rječniku ćemo videti da je farisizam $t \bar{a} g ̆$ dao arapskom jeziku koren *twğ, od kog su izvedene sledeće reči tatwī̆g (krunisanje), tāğāalyatūğultawğ (okruniti se, b. krunisan; itd). Persijska reč baht je još bolji primer visokog stepena adaptacije, zbog svog trokonsonantizma. Od nje su lako izvedeni pridevi po arapskim tvorbenim obrascima: bahīt, mubhat i mabhhüt (sretan). Svoj derivacioni potencijal u arapskom ostvarila je i reč ğawrab, koja se uklopila u četvororadikalnu paradigmu, pogodnu za asimilaciju stranih reči, pa dala čak i glagol ğawraba (obući /kome/ čarape), dok je reč dihlīz dala glagol tadahlaza (prolaziti kroz hodnik)...

\subsection{Značenje reči}

Broj reči koje imaju samo jedno značenje, koliko smo to mogli da utvrdimo na osnovu prevodnih ekvivalenata u bosanskom delu Rječnika, iznosi 41. Ipak, moramo napomenuti da jedno značenje nije nužno i jedan prevodni ekvivalent. Nekada je za jednoznačnu reč u arapskom navedeno 
dva ili više prevodna ekvivalenta u bosanskom delu Rječnika. Na primer, za farisizam zanğ̄ $r / z i n g ̆ \grave{\imath} r$ Muftić navodi prevodni ekvivalent lanac, reč koja je u frekventnoj upotrebi danas, i njen sinonim, sindžir, koji kod nas ima status arhaizma. Slično važi i za druge parove sinonima, različite etimologije, frekvetnosti i regionalne rasprostranjenosti (spužve, sunđeri; oktopod, hobotnica; vrag, đavo, demon, iblis; šoljica, fildžan i sl.).

Ostale ekscerpirane reči, čiji broj iznosi 59, razvile su polisemiju $\mathrm{u}$ arapskom, što se vidi iz njihovih prevodnih ekvivalenata u bosanskom delu Rječnika, čija su različita značenja odvojena tačkom i zapetom. U Rječniku ćemo videti da sirska reč $b \bar{l}$ ' $a$ u arapskom označava dva različita pojma - crkva i sinagoga, dok za reč dumya, koja takođe dolazi iz sirskog, Rječnik navodi još više značenja: kip, statua, spomenik; slika; idol; lutka; marioneta; žena; maneken; utvara. Kod 7 reči je primećeno da su, pored opštejezičkog značenja, poprimile i sekundarno terminološko, kao na primer latinizam furn za ležište /lokomotive/ ili farisizam usțuwāna za bubanj /turbine/ ili rezervoar /gasa/ i sl.

Prema pojmovima koje označavaju, ekscerpirane reči se mogu podeliti u više tematskih grupa, mada one nisu precizno odvojive, naročito zbog toga što je Muftić beležio i primarno značenje svake reči, zbog kojeg je došlo do pozajmljivanja, i ona sekundarna značenja, koja su nastala kasnije, i to „bez diferenciranja izvesnih značenja prema epohama istorije jezika i jasnijeg ukazivanja na veću i manju frekvenciju upotrebe pojedinih oblika“" (Tanasković, 1976: 201). Preciznu podelu na tematske grupe otežava i činjenica da jedna reč pored više opšteupotrebnih značenja može imati i bar jedno terminološko. Ipak, možemo zaključiti da najveću tematsku grupu čine religijski termini, a frekventno su zastupljeni i naučni pojmovi, lokalno obojeni termini i artefakti koje su Arapima donele razvijenije civilizacije.

\subsection{Zajednički leksički sloj u arapskom i bosanskom delu Rječnika}

O zajedničkom leksičkom sloju u arapskom i bosanskom delu Rječnika svedoči čak 53 reči. Neke od ovih reči su do nas došle kao internacionalizmi, a pretežno su indoevropske etimologije, kao na primer farsizam

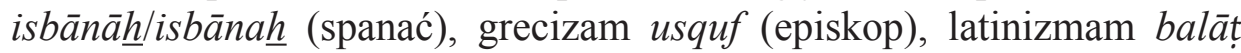
(palata), sanskritizam zanğabül (đumbir), ili pojedini internacionalizmi iz 
judeohrišćanske tradicije, poput hebraizama šayțān (sotona) i āmīn/amīn (amin). Deo zajedničkog leksičkog sloja kod nas spada u turcizme, jer ovim terminom nazivamo sve reči koje smo preuzeli iz turskog, bez obzira na njihovu izvornu etimologiju (Muftić, 1961: 5). Takvi su, na primer, sledeći farisizmi: banğara (pendžer), ğawrab (čarapa) ili sirwāl (šalvare). Jedan broj reči iz zajedničkog leksičkog sloja došao je do nas iz arapskog, koji je, kao jezik islamske religije, bio pristupačan svim muslimanima. Ovakve reči nazivamo arabizmima. U ekscerpiranom materijalu, naćićemo etiopsku reč minbar (mimbera), koja bismo mogli nazvati arabizmom, s obzirom na jezik-posrednik preko koga je došla do nas (Muftić, 1961: $5,20)$. Procenat reči koje čine zajednički leksički sloj bi bio još veći da je Muftić uključio neke naše reči koji su izostale, kao što je furuna (za latinizam furn) ili mihrab (od miḥrāb), kako često nazivamo nišu u zidu džamije.

\section{Umesto zaključka - značaj istraživanja i mogućnosti za dalja istraživanja}

Iako su prethodno izneti podaci o formalnoj i semantičkoj adaptaciji stranih reči u jeziku-primaocu već poznati opštoj lingvistici, dok su grafofonološke i morfološke karakteristike stranih reči u arapskom dobro poznate $\mathrm{u}$ arabističkim krugovima, ipak ovaj rad predstavlja jedan novi doprinos arabističkoj dijahronijskoj i komparativnoj lingvistici, i to pre svega zbog izvora iz kog je eskcerpiran jezički materijal. Muftićev Rječnik, kao iscrpna kompilacija leksikografskih izvora, koja objedinjuje jezičko blago rečnika različitih obima i namena, navodeći pritom ne samo frekventne oblike i značenja, već i one koji su izašli iz žive upotrebe, bez pretenzija za propiše upotrebu pojedinih oblika nasuprot nekim drugima, predstavlja solidnu osnovu za proučavanje stranih reči u arapskom jeziku sa dijahronijskog stanovišta. Budući da je Rječnik bilingvalan i da u oba jezika nailazimo na zajednički sloj reči stranog porekla, koje funkcionišu kao internacionalizmi u zapadnoevropskom i orijentalno-islamskom kulturnom krugu, on može biti od koristi i komparativnoj lingvistici.

Ovo bi se istraživanje moglo dopuniti i analizom stranih reči koje su u arapski ušle u kasnijim fazama razvoja, pre svega turcizmima, koje Muftićev Rječnik iscrpno beleži. Rezultati se mogu uporediti i sa pozaj- 
mljenicama koje su u savremeni arapski jezik ušle u prošlom i ovom veku, pretežno iz francuskog i engleskog. Verujemo da bi poređenje reči stranog porekla u klasičnom arapskom sa kasnijim pozajmljenicama, pokazalo da postoje različite obrasci formalne adaptacije i semantičkog razvoja datih reči, uslovljeni vremenom ulaska reči u arapski jezik, načinom pozamljivanja (pismeno/usmeno, direktno/indirektno), strukturom jezika-davaoca i drugim faktorima.

\section{LITERATURA}

al-Munğid fí al-luġa al- 'arabiyya al-mu'așira (țab'a tāniya). (2001). Bayrūt: Dār al-mašriq.

al-Qinai, J. B. S. (2000). Morphophonemics of loanwords in Arabic. Studies in the Linguistic Sciences, 30 (2), 1-25.

Bāsil, G. M. (2002). Al-Mu'arrab wa al-dahîl fì al-lugia al-'arabiyya (baḥt muqaddam li nayl darağa al-duktūrā). Islāmābād: Kulliyya al-lugàa al'arabiyya.

Božović, R. (2018). Istorija arapske klasične i narodne književnosti. Beograd: Zavod za udžbenike.

Duraković, E. (2004). In memoriam: Prof. Dr. Teufik Muftić. Prilozi za orijentalnu filologiju, 54, 11-16.

Espozito, Dž. L. (2002) Oksfordska istorija islama. Beograd: Clio.

Fraenkel, S. (1886). Die aramäischen Fremdwörter im Arabischen. Leiden: E. J. Brill.

Gabrijeli, F. (1985). Arapska književnost. Sarajevo: Svjetlost.

Hiti, F. (1988). Istorija Arapa: od najstarijih vremena do danas. Sarajevo: Veselin Masleša.

Holes, C. (2004). Modern Arabic: Structures, Functions, and Varieties. Washington D.C: Georgetown University Press.

Hurani, A. (2013). Istorija arapskih naroda. Beograd: Clio.

Janković, S. (1987). Arapski izgovor s osnovama arapskog pisma. Sarajevo: Svjetlost.

Jeffery, A. (1938). The Foreign Vocabulary of the Quran. Baroda: Oriental Institute.

Kico, M. (2003). Arapska jezikoslovna znanost: Općelingvistička utemeljenja i specifična određenja. Sarajevo: Fakultet islamskih nauka. 
Klajn, I. (1966). Uslovi za asimilaciju stranih reči. Anali filološkog fakulteta, 6, 433-443.

Klajn, I. (1971). Uticaji engleskog jezika u italijanskom. Beograd: Filološki fakultet.

Lewis, B. (1993). The Arabs in History. Oxford University Press.

Lewis, B. (2001). The Middle East: 2000 Years of History from the Rise of Christianity to the Present Day. Phoenix Press.

Mansfield, P. (1992). A History of the Middle East. London: Penguin Books.

Ma'rūf, N. (1960). al-Madhal fì tārīh al-ḥad̄āra al- 'arabiyya. Bag̉dād: Maṭba'a al-'anī.

Mitrović, A. (2010). Mesto kontrastivne analize u lingvističkoj arabistici. U I. Klajn \& P. Piper (ur.), Kontrastivna proučavanja srpskog jezika: pravci $i$ rezultati (191-217). Beograd: SANU.

Moscati, S., Spitaler, A., Ullendorff, E., \& Von Soden, W. (1964). An Introduction to the Comparative Grammar of the Semitic Languages. Wiesbaden: Otto Harrassorwitz.

Muftić, T. (1961). O arabizmima u srpskohrvatskom jeziku. Prilozi za orijentalnu filologiju, X-XI, 5-29.

Muftić, T. (1973). Arapsko-srpskohrvatski rječnik I-II. Sarajevo: Starješinstvo islamske zajednice.

Muftić, T. (1997). Arapsko-bosanski rječnik. Sarajevo: el-Kalem.

Muftić, T. (1998). Gramatika arapskoga jezika. Sarajevo: Ljiljan.

Nahla al-Yasū'ī, R. (1945). Ġarā 'ib al-lugia al- 'arabiyya. Halab: Maṭba'a Iḥsān.

Nöldeke, T. (1910). Neue Beiträge zur semitischen Sprachwissenschaft. Straßburg: Karl J. Trübner.

Nuri Hadžić, O. (1987). Muhammed A. S. i Kur'an: osvrt na historiju islamske kulture. Zagreb: Islamska zajednica.

Online Etymology Dictionary < https://www.etymonline.com/>

Schwally, F. (1898). Lexikalische Studien. Zeitschrift der Deutschen Morgenländischen Gesellschaft, 52, 132-149.

Tanasković, D. (1976). Prvi arapsko-srpskohrvatski rečnik. Filološki pregled, III, 198-202.

Tanasković, D. (1982). Arapski jezik u savremenom Tunisu (diglosija i bilingvizam). Beograd: Filološki fakultet.

'Ubayd, 'A. al-L. (2001). Dawr al-tawtīq wa al-'i'lām al-muștalahịyyayn fỉ tațwīr al-mușțalahāat al-'arabiyya wa 'intišārihā. al-Lisān al-'arabiyy, 52, 113 127. 
Ivana R. Gligorijević

\section{Ivana Gligorijević}

\section{FOREIGN WORDS IN CLASSICAL ARABIC: TEUFIK MUFTIĆ'S ARABIC-BOSNIAN DICTIONARY}

\section{Summary}

It is common knowledge that loanwords constitute a significant portion of the Classical Arabic vocabulary. In this paper we examine how loanwords are represented in Teufik Muftić's Arabic-Bosnian Dictionary (formerly Arabic-SerboCroatian Dictionary), which is known for its thorough and comprehensive listing of Arabic vocabulary. Our hypothesis was that the Dictionary can give us new insights into this layer of classical Arabic lexicon, with some specific morphological and semantic rules that govern it. In the first part of this study we described a historical framework in which language contacts took place. We have listed 100 examples from the most common donor-languages, in proportion to the extent of their impact on Arabic. During the early stages of its development, Arabic was mostly borrowing from Persian, Greek, Syriac and Latin, and less from Hebrew, Ethiopian, Sanskrit, Acadian and other languages. Each word was cross-checked in various relevant dictionaries and historical reference books, although these sources were not always consistent, when it comes to etymology. The words are then excerpted from the Arabic-Bosnian Dictionary and analyzed from different standpoints. The analysis of the Arabic part of the excerpted words has shown a high degree of adaptation at both graphophonological and morphological levels, to the extent that some loanwords are not even treated as words of foreign origin in Dictionary entries. Some loanwords that are fully-adapted became roots for further derivations, while many of them developed broken plurals in Arabic. The analysis of the Bosnian part of the Dictionary has shown a rich polysemantic structure of most loanwords, while words that did not exhibit any secondary meanings are fewer. It is also noticed that many loanwords are present in both Arabic and Bosnian part of the Dictionary, where their came via different routes. The most common thematic groups are the following: religion, science, administration, botany, agriculture, professions, clothing, artifacts, philosophy etc. We tried to define the status of loanwords in Classical Arabic and pinpoint some of their morphological and semantic peculiarities, which are presented in the Dictionary. However, many issues remained unresolved and call for more extensive analysis. For instance, subsequent studies could provide an in-depth analysis of loanwords in Modern Standard Arabic. A comparison can be drawn between loanword in Classical Arabic and Modern Standard Arabic.

Key words: Foreign Words, Linguistic Borrowing, Adaptation of Loanwords, Classical Arabic Language, Arabic-Bosnian Dictionary, Teufik Muftić. 